\title{
Bioassay Measurements of
}

Individuals Living Near

the U. S. Department of

Energy's Hanford Site

in Washington State -

Fall 1985
M. J. Sula
D. E. Bihl

May 1986

Prepared for the U.S. Department of Energy under Contract DE-AC06-76RLO 1830

Pacific Northwest Laboratory Operated for the U.S. Department of Energy by Battelle Memorial Institute 


\title{
DISCLAIMER
}

This report was prepared as an account of work sponsored by an agency of the United States Government. Neither the United States Government nor any agency thereof, nor any of their employees, makes any warranty, express or implied, or assumes any legal liability or responsibility for the accuracy, completeness, or usefulness of any information, apparatus, product, or process disclosed, or represents that its use would not infringe privately owned rights. Reference herein to any specific commercial product, process, or service by trade name, trademark, manufacturer, or otherwise, does not necessarily constitute or imply its endorsement, recommendation, or favoring by the United States Government or any agency thereof. The views and opinions of authors expressed herein do not necessarily state or reflect those of the United States Government or any agency thereof.

\author{
PACIFIC NORTHWEST LABORATORY \\ operated by \\ BATTELLE \\ for the \\ UNITED STATES DEPARTMENT OF ENERGY \\ under Contract DE-AC06-76RLO 1830
}

\begin{tabular}{|c|c|}
\hline \multirow{2}{*}{\multicolumn{2}{|c|}{ Printed in the United States of America }} \\
\hline & \\
\hline \multicolumn{2}{|c|}{$\begin{array}{l}\text { Available from } \\
\text { National Technical Information Service }\end{array}$} \\
\hline \multirow{2}{*}{\multicolumn{2}{|c|}{$\begin{array}{l}\text { National Technical Information Service } \\
\text { United States Department of Commerce }\end{array}$}} \\
\hline & \\
\hline \multicolumn{2}{|c|}{$\begin{array}{c}5285 \text { Port Royal Road } \\
\text { Springfield, Virginia } 22161\end{array}$} \\
\hline \multirow{2}{*}{\multicolumn{2}{|c|}{$\begin{array}{l}\text { NTIS Price Codes } \\
\text { Microfiche } A 01\end{array}$}} \\
\hline & \\
\hline \multicolumn{2}{|c|}{ Printed Copy } \\
\hline Pages & $\begin{array}{l}\text { Price } \\
\text { Codes }\end{array}$ \\
\hline $001-025$ & $\mathrm{~A} 02$ \\
\hline 026-050 & 103 \\
\hline 051-075 & A04 \\
\hline 076-100 & A0S \\
\hline $101-125$ & A06 \\
\hline $126-150$ & A07 \\
\hline $151-175$ & $\mathrm{~A} 08$ \\
\hline $176-200$ & $\mathrm{~A} 09$ \\
\hline 201-225 & A010 \\
\hline $226-250$ & A011 \\
\hline $251-275$ & A012 \\
\hline $276-300$ & A013 \\
\hline
\end{tabular}


BIOASSAY MEASUREMENTS OF INOIVIDUALS

LIVING NEAR THE U.S. DEPARTMENT OF ENERGY'S HANFORD SITE IN WASHINGTON STATE - FALL 1985

M. J. Sula

D. E. Biht

May 1986

Prepared for the U.S. Department of Energy under Contract DE-AC06-76RL0-1830

Pacific Northwest Laboratory Richland, Washington 99352 
.

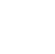




\section{PREFACE}

In October of 1985, the Department of Energy (DOE) conducted a workshop at Edwin Markham School in Franklin County on Hanford environmental monitoring activities. One of the primary issues discussed during that workshop was the uncertainty and concern on the part of many residents in northwest Franklin County regarding potential health effects of past and ongoing Hanford operations.

To provide those individuals with additional information regarding potential Hanford impacts on their health, the Manager of the DOE's Richland Operations office announced during the workshop that DOE's resources would be avai $i$ able to residents of northwest Franklin County for the evaluation of internally deposited radioactive materials.

Following that announcement, the Pacific Northwest Laboratory, operated by Battelle Memorial Institute under contract to DOE, provided whole body counts and analyses of urine samples on request to the residents of northwest Franklin county. This report describes those measurements and summarizes the resulting data. 


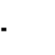




\section{SUPI:MARY}

In the fall of 1985, at the request of the U.S. Department of Energy's Richland Operations office (DOE-RL), the Pacific Northwest Laboratory provided special bioassay measurements to individuals living near the Hanford Site in eastern Washington.

The purpose of the bioassay measurements was to provide individuals, living within a specific area near the Hanford Site, information on the current levels of radionuclides in their bodies. The measurements included whole body counter (in vivo) examinations and urine sample analyses for detecting the presence of major radionuclides related to current and historical operations at Hanford.

Notifications of the special measurements were sent by letter to 515 residences in north Franklin County. Eighty-nine individuals from 52 of the 515 residences requested and received whole body counts. of these, 32 also provided urine samples.

The measurements gave no evidence of unusual levels of radioactivity in any individual. The ability of bloassay measurements to detect the presence of radioactivity in an individual following an exposure is dependent on the quality of the measurement and the nature of the exposure. This report includes a discussion of the capability, under various circumstances, of the measurements that were provided. 
. 


\section{CONTENTS}

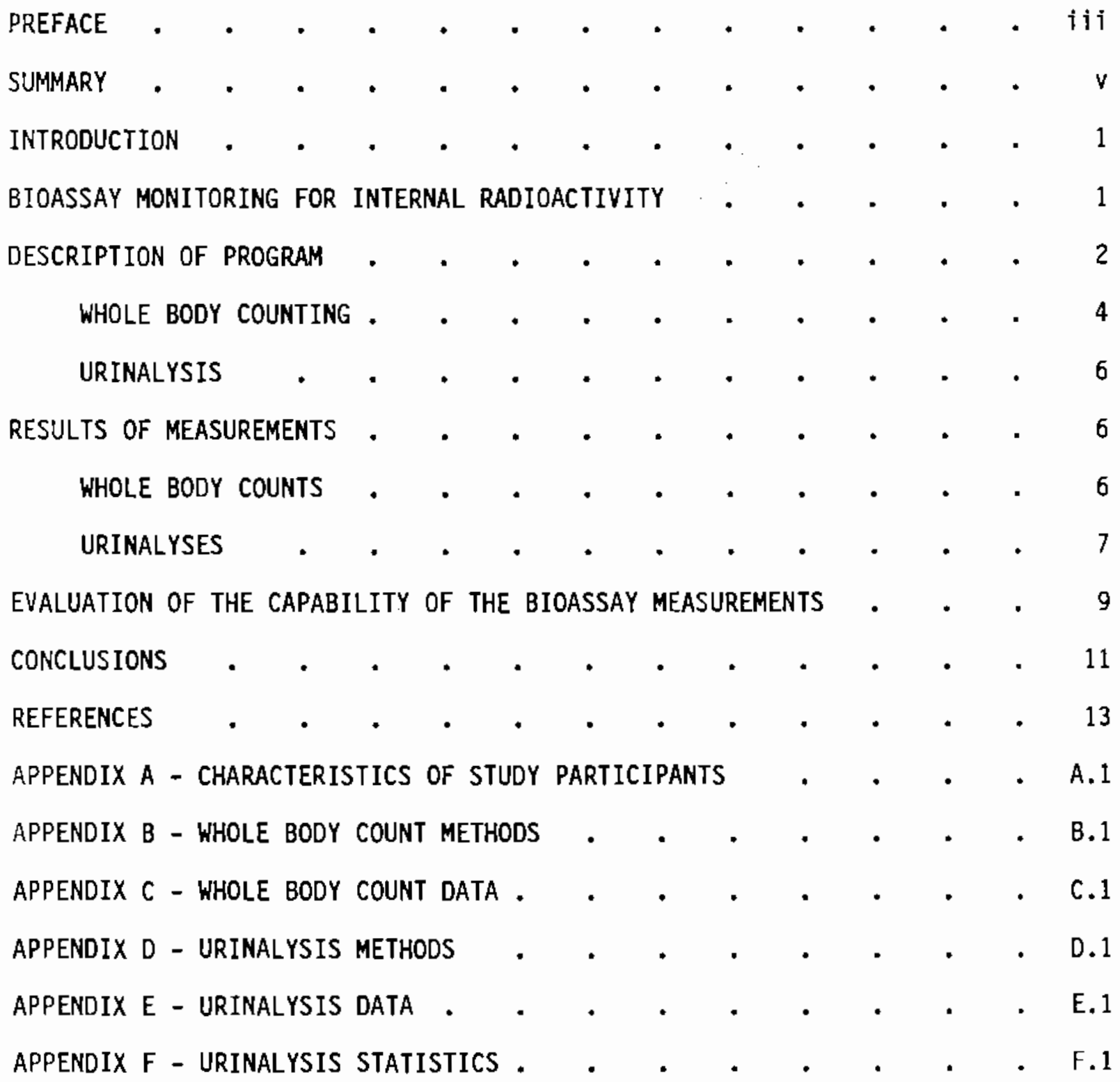




\section{FIGURES}

1 Map of Area Within Which Notification Letters Were Sent . $\quad 3$

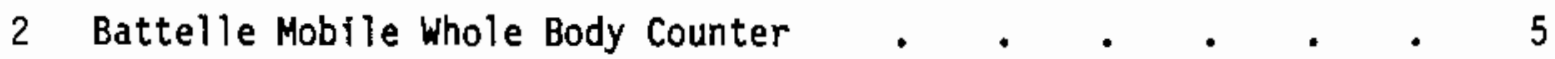

C.1 Summary of Whole Body Count Spectra . . . . . . . c.3

C.2 Comparison of Spectra Obtalned From Individuals with Interfering Levels of Natural Radioactivity on Clothing . . C.4

\section{TABLES}

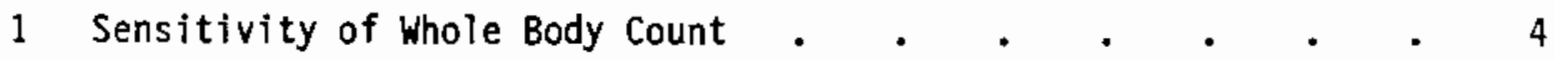

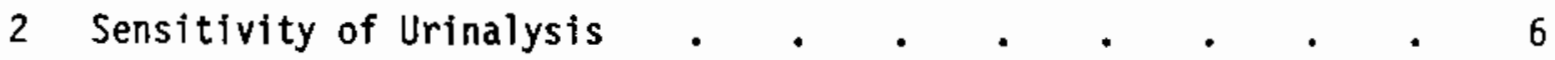

3 Sensitivity of Bioassay Measurements . * . . . . . 10

B.1 Calibration Factors for BOMAB Phantom . . . . . . B.2

C.1 Summary of Whole Body Count Spectrum Analyses . . . . + c.2

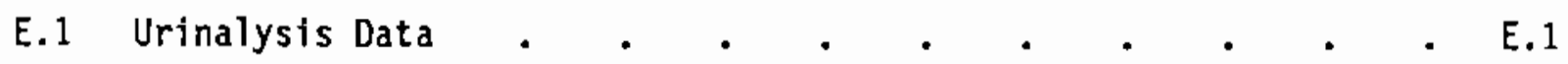

F.1 Strontium-90 Results Uncorrected for Reagent Bias . • • F.2

F.2 Reagent Blanks . . . . . . . . . . . . . F.3 


\section{INTRODUCTION}

This report describes special public bioassay measurements performed by the Pacific Northwest Laboratory, operated by Battelle Memorial Institute, in the fall of 1985 at the request of the Manager of the Richland Operations Office $(R L)$ of the Department of Energy (DOE). The purpose of the measurements was to provide information to individuals living within a specific area near the Hanford Site regarding the current levels of radionuclides in their bodies.

Whole body counts were performed on 89 individuals. Thirty-two of these people also elected to provide samples for urinalysis. These measurements were designed to detect major radionuclides related to the current and historical operations at Hanford.

\section{BIOASSAY MONITORING FOR INTERNAL RADIOACTIVITY}

Bioassay monitoring is a common procedure for detecting the presence of foreign substances in the body. Public familiarity with the use of bioassay techniques has been recently heightened by news articles about the testing of professional athletes for certain drugs. Bioassay measurements are equally useful for determining the presence of various radioactive materials in the body. Such measurements are commonly performed in the nuclear industry to determine worker exposure to internal radioactivity.

There are two general types of bioassay measurements: direct and indirect. Direct methods use a sensitive radiation detector, called a whole body counter, to measure the radiations that are emitted by radioactive materials in the body. Indirect measurements are performed by measuring the radioactivity in excreta from the body. The indirect method indicates the presence of radioactive material in the body by inference from the presence of material in the excreta. There are advantages and limitations associated with both the direct and the indirect bioassay methods.

Direct bioassay measurements are relatively easy to perform, are capable of detecting several radioactive materials from a single measurement, and provide a direct measure of the amount of the radioactive materials present 
in the body. To detect a specific radioactive material, two criteria must be met: 1) the radioactive material present in the body must emit radiations that can escape from the body and enter the detector of the whole body counter and 2) the radiation detector must be sensitive to the incoming radiations. The capability for detecting a particular type of radioactive material thus depends on the properties of the material and the properties of the radiation detector. The Hanford Mobile whole Body Counter can detect gamma-ray-emitting radionuclides such as potassium-40, cobalt-60, cesium-137, jodine-131, and ruthenium-106. However, the Hanford Mobile Whole Body Counter cannot be used for the detection of some radionuclides, including plutonium, radiostrontium, and tritium.

The indirect bioassay method is potentially effective for measuring all radioactive materials including plutonium, radiostrontium, and tritium. The criterion for indirect bioassay is only that the material in the body is excreted via the pathway measured. However, the disadvantages of the indirect method are that a separate test must be performed for each type of material and the amount of the material in the body must be inferred based on the quantity measured in the excreta. These inferences are made using mathematical models that describe the excretion of materials following their intake into the body.

\section{DESCRIPTION OF PROGRAM}

Bjoassay measurements were performed on individuals living near the Hanford site. The measurements, performed by the Pacific Northwest Laboratory in November and December of 1985, included both whole body counting and urinalysis.

Recipients of the measurements were individuals living in Franklin County near the eastern boundary of the Hanford site as defined by an arc of radius ten miles from the Washington Public Power Supply System's WNP-2 plant (Figure 1). This area was designated by the Department of Energy. 


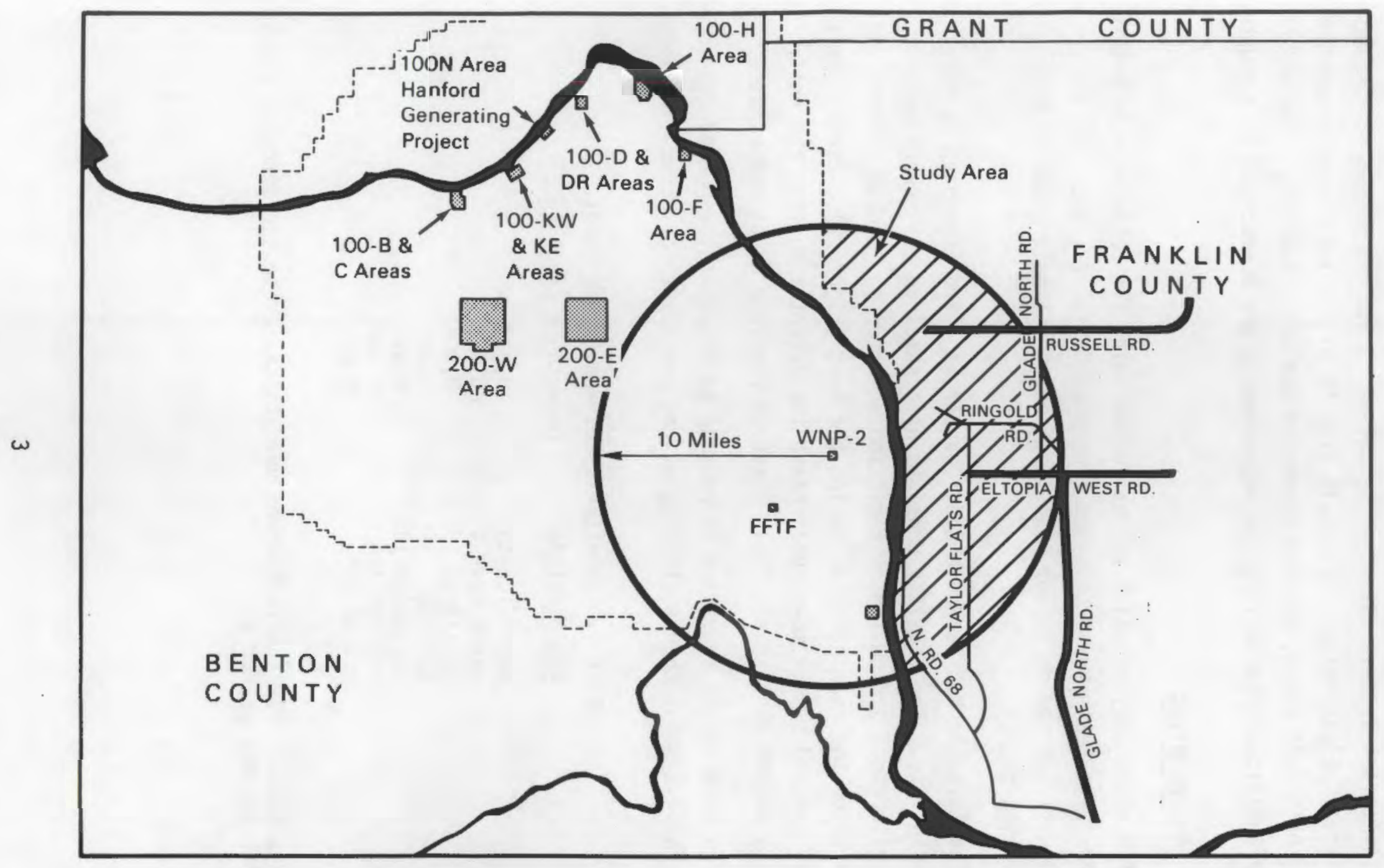

FIGURE 1. Map of Area Within Which Notification Letters Were Sent 
Invitation letters were sent by DOE-RL to 515 residences in the designated area. Eighty-nine individuals from 52 of the residences requested whole body counts. Of these, 32 also requested the urine analyses. Characteristics of the individuals requesting the measurements are summarized in Appendix A.

\section{WHOLE BODY COUNTING}

The whole body counting was performed using the Battelle Mobile Whole Body Counter. The tests were conducted from November 12-27, 1985, at the Chiawana Grange Hall located on Taylor Flats Road about 0.1 mile south of Mathews Corner in Franklin County.

The Battelle Mobile whole Body Counter is a truck-mounted in vivo radioassay facility. The facility consists of a shielded 12-inch diameter by 4-inch deep cylindrical sodium iodide radiation detector positioned above a sliding pad on which the examinee lies during the test. (Figure 2). During the examination, the pad slowly moves underneath the detector so that the entire length of the examinee is scanned. This traverse requires about ten minutes.

The detector is sensitive to photons in the energy range of 150 to 5000 keV. Table 1 shows the sensitivity of the procedure for several radionuclides.

$\begin{array}{ll}\begin{array}{c}\text { TABLE 1. Sensitivity of Whole Body Count } \\ \text { Radionuclide }\end{array} & \begin{array}{c}\text { Detectable Level }(\mu \mathrm{Ci}) \\ \text { potassium-40 }\end{array} \\ \text { manganese-54 } & 0.018 \\ \text { cobalt-60 } & 0.003 \\ \text { zinc-65 } & 0.003 \\ \text { ruthenium-106 } & 0.005 \\ \text { iodine-131 } & 0.017 \\ \text { cesium-137 } & 0.003 \\ & 0.003\end{array}$

Appendix $B$ describes the techniques used to calibrate the detector and to evaluate the measurements. 


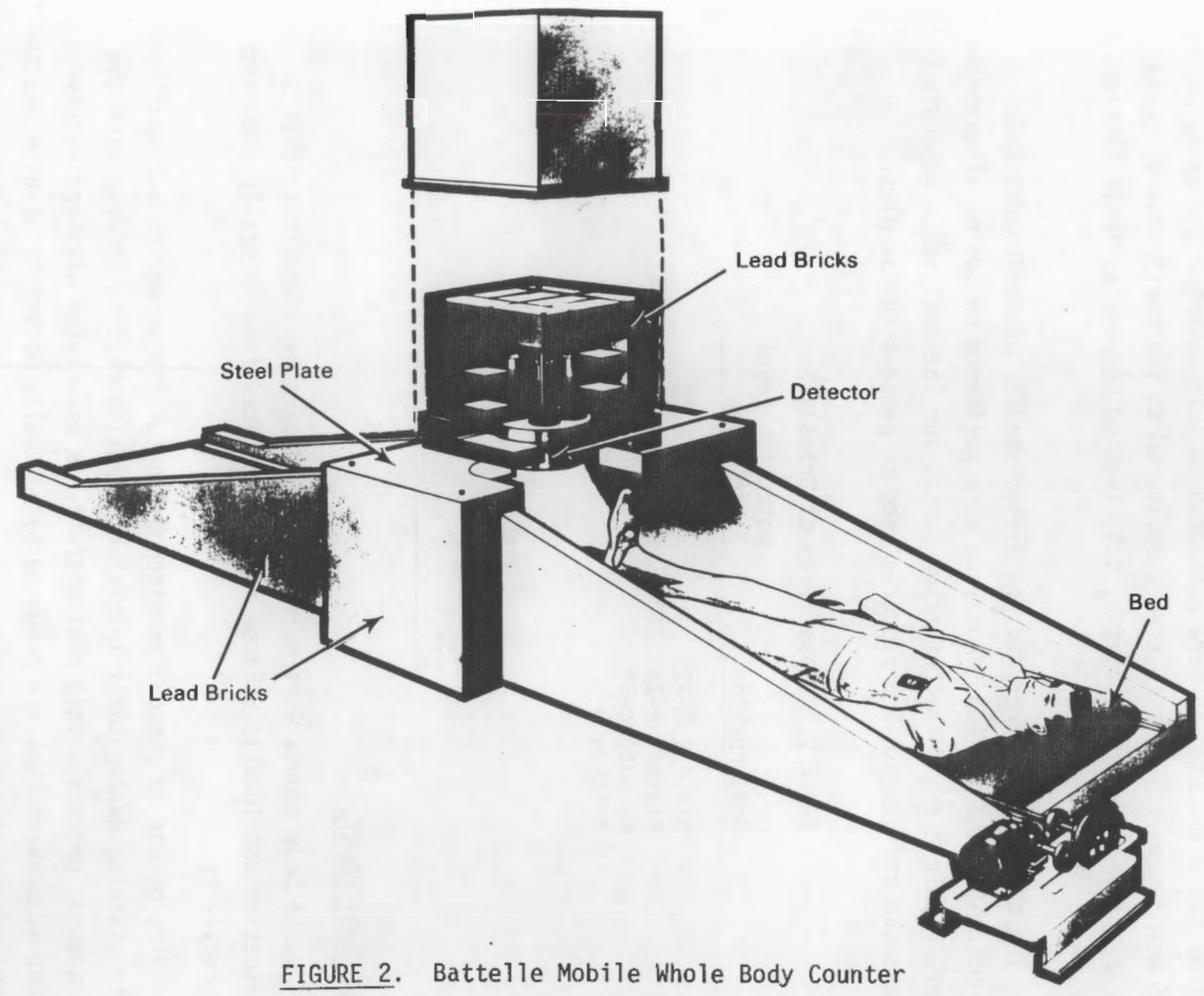




\section{URINALYSIS}

Indirect bioassay monitoring was performed using urine as the excreta medium. The urine samples were collected in late November and early December 1985 using sampling kits that were delivered to the participants' residences. Sample analyses were performed by U.S. Testing Company at their Richland, Washington, laboratory.

The samples were analyzed for plutonium-238, plutonium-239/240, strontium-90, and tritium. Analyses were performed on $500 \mathrm{~mL}$ aliquots of urine. Table 2 shows the detection levels for the analyses. Appendix D describes the radiochemical procedures used to process the samples.

\begin{tabular}{lc}
$\begin{array}{l}\text { TABLE 2. Sensitivity of Urinalysis } \\
\text { Radionuclide }\end{array}$ & $\begin{array}{c}\text { Detection Leve1 } \\
\text { (pCi/L) }\end{array}$ \\
\cline { 2 - 2 } plutonium-238 & 0.02 \\
plutonium-239,240 & 0.02 \\
strontium-90 & 2.0 \\
tritium & 2000
\end{tabular}

\section{RESULTS OF MEASUREMENTS}

WHOLE BODY COUNTS

Whole body counts were performed on 89 persons. One individual's examination was invalid because of interferences from naturally occurring radioactivity.

Nine of the 89 persons examined had naturally occurring radioactivity on their clothing during their initial examination that interfered with the measurement process. This radioactivity is associated with radioactive gases in the atmosphere that are produced by naturally occurring uranium and thorium in the earth. The radioactive gases are radon and thoron, and they produce radioactive decay products. If present at sufficient levels, this background radiation inhibits the detection of low levels of radioactivity in the body. 
Except for one case, the interferences were reduced to within acceptable levels by having the individual change to cotton coveralls that were provided for this purpose. In all of these cases, the individual had arrived wearing clothing made of synthetic materials. Synthetic materials can generate a static charge that attracts dust particles in the atmosphere. The products of the naturally occurring radioactive gases are attached to the dust particles. In the one uncorrected case, the individual did not wish a reexamination. A review of that individual's measurement result showed the characteristic interferences of the naturally occurring radioactivity. The interferences precluded an effective determination of the presence or absence of Hanford-related radionuclides.

Individually, none of the 88 valid examinations showed detectable levels of internal radioactivity except for naturally occurring potassium-40. Potassium-40 levels in the subjects ranged from $0.048 \mathrm{\mu Cj}$ in a 4-year-old child to $0.16 \mu \mathrm{Cl}$ in an adult male. These levels are in the range that would be expected in the U.S. population (UNSCEAR 1972).

Analysis of grouped data can sometimes enable detection of small amounts of radioactivity present in a study group at levels below that which can be detected in a single individual. Therefore, spectra for the 88 measurements were summed and visually inspected for indications of apparent radioactivity. No indications of such activity from radionuclides of potential Hanford origin were observed. However, the sensitivity of the analysis was limited by the prevalence of low levels of naturally occurring radionuclides in the study group. The summed spectrum is shown in Figure $c .1$ of Appendix $C$. The sensitivity of the procedure could be improved by having each subfect shower thoroughly and change to clean cotton clothing just before the examination.

\section{URINALYSES}

Participants in the urine testing program were a subset of the group that received whole body counts. Thirty-two of the 35 persons requesting the test provided a urine sample. No measurement result for an individual exceeded its corresponding analytical detection limit. 
The data for individual sample analyses are listed in Appendix $E$. These data are the products of the analytical process in which the activity indicated by the measurement is reported along with the uncertainty associated with the measurement.

The analytical results for the strontium-90 and plutonium analyses were compared to the results obtained from performing the analytical procedure without any urine (i.e., a reagent blank). Using a one-tailed test at the 95\% significance level, the urine data were tested to determine if there was a statistically significant difference in the analytical results obtained from the samples compared to the reagent blanks. This test showed that, for all three radionuclides, the urine analyses and the reagent blank analyses were not statistically different. Appendix $F$ provides additional detail on the statistical tests that were performed.

The tritium data could not be tested the same way because the analytical procedure was based on a comparison to a reagent blank. The tritium data were therefore tested against the hypothesis that the samples actually contained zero activity. The test was performed using a one-tailed t-test at the $95 \%$ significance level. This test indicated a slightly positive bias. The mean and standard error of the mean for the grouped tritium data were $240 \pm 110$ picocuries per liter. Since tritium is a naturally occurring radionuclide and was introduced into the environment during the atmospheric nuclear testing of the 1960s, its presence in environmental and biological media is expected.

The amount of tritium excreted dally from the body is nearly the same as the amount taken daily into the body. The concentration of tritium in urine is thus about the same as its concentration in the water taken into the body. The bias observed for tritium in the grouped samples can thus be compared to levels of tritium in the environment to determine if the Tevels are within the range that would be predicted by environmental samples. Based on the results of environmental samples collected in the Hanford environs during 1984 (Price et al. 1985), the observed concentration bias for tritium in urine is similar to the concentrations observed in various environmental media in 
the vicinity of as well as away from the Hanford Site. Additionally, the observed range for tritium in drinking water across the United States as measured by the Environmental Protection Agency (1985) ranges from 100-400 picocuries per liter. Thus, tritium levels from the analysis of grouped data are not considered unusual.

\section{EVALUATION OF THE CAPABILITY OF THE BIOASSAY MEASUREMENTS}

Bioassay measurements readily provide a qualitative indication of the presence of radioactive materials in the body. However, in order to evaluate the significance of the presence of the material in terms of potential health impact, additional information is necessary. Specifically, the consequence of radioactive material in the body is a function of the amount of energy deposited in body tissues by the radiations emitted from the material. Bioassay measurements do not provide a direct measure of the total amount of energy deposited in tissues following internal exposure to radioactive material. However, mathematical models can be used to predict the relationship between a bioassay measurement and a corresponding total energy deposition for given circumstances.

Estimates of the sensitivity of the bioassay measurements were made by using the mathematical models to predict, under various circumstances, the amount of exposure that could have been detected. The models and parameters for radionuclide retention and excretion were those recommended by the International Commission on Radiological Protection (ICRP) as described in their Publication 30 (1979). Both chronic and acute intakes via inhalation and ingestion were considered, and the time from the initial intake to the bioassay measurement was varied over 40 years.

The effective dose equivalent that would be received by an individual over a 50-year period following an intake (or the onset of intake in the case of chronic exposures) detectable by a bioassay measurenent, was calculated. To simplify their presentation, these doses are expressed in terms of multiples of the 5 rem whole body dose that is received from the natural radiation background during a 50-year period. The results of the calculations are summarized in Table 3 . 
TABLE 3. Sensitivity of Bioassay Measurements

\begin{tabular}{|c|c|c|c|c|c|c|c|}
\hline \multirow[b]{2}{*}{ EXPOSURE } & \multirow[b]{2}{*}{ MATERIAL. } & \multicolumn{6}{|c|}{$\begin{array}{l}\text { Detectable Dose } \\
\text { (multiples of environmental background) }\end{array}$} \\
\hline & & 1 & 2 & -5 & 10 & 20 & -40 \\
\hline \multicolumn{8}{|c|}{ Acute Inhalation } \\
\hline & $\begin{array}{l}\text { Tritium } \\
\text { Cobalt-60 }\end{array}$ & $<\overline{0.1}$ & $<\overrightarrow{0.1}$ & $<0.1$ & $\overline{0.1}$ & 10 & $=$ \\
\hline & Strontium-90 & $<0.1$ & $=0.1$ & 0.1 & 0.4 & 3 & - \\
\hline & Ruthen i um-106 & $<0.1$ & $<0.1$ & 0.3 & -- & -- & -- \\
\hline & Iodine-131 & -- & -- & -- & -- & -- & -- \\
\hline & Cesium-137 & $<0.1$ & $<0.1$ & 4 & -- & -- & -- \\
\hline & Plutonium & 2 & 2 & 2 & 3 & 3 & 4 \\
\hline
\end{tabular}

Acute Ingestion

$\begin{array}{lcccccc}\text { Tritium } & -- & -- & -- & -- & -- & -- \\ \text { Cobalt-60 } & <0.1 & <0.1 & <0.1 & 0.1 & 9 & -- \\ \text { Strontium-90 } & <0.1 & <0.1 & -0.1 & <0.1 & 0.2 & 1 \\ \text { Ruthenium-106 } & <0.1 & <0.1 & 0.8 & -- & -- & -- \\ \text { Iodine-131 } & -- & -- & -- & -- & -- & -- \\ \text { Cesium-137 } & 0.1 & 0.1 & 4 & -- & -- & -- \\ \text { Plutonium } & 2 & 3 & 3 & 3 & 3 & 4\end{array}$

Chronic Inhalation

Chronic Ingestion

$\begin{array}{lcccccc}\text { Tritium } & <0.1 & <0.1 & <0.1 & <0.1 & <0.1 & <0.1 \\ \text { Cobalt-60 } & <0.1 & <0.1 & <0.1 & <0.1 & <0.1 & <0.1 \\ \text { Strontium-90 } & 1 & 0.7 & 0.4 & 0.3 & 0.3 & 0.3 \\ \text { Ruthenium-106 } & 0.8 & 0.6 & 0.5 & 0.5 & 0.5 & 0.5 \\ \text { Iodine-131 } & 0.2 & 0.2 & 0.2 & 0.2 & 0.2 & 0.2 \\ \text { Cesium-137 } & <0.1 & <0.1 & <0.1 & <0.1 & <0.1 & <0.1 \\ \text { Plutonium } & 36 & 20 & 10 & 3 & 3 & 2\end{array}$

$\begin{array}{lrrrrrr}\text { Tritium } & <0.1 & <0.1 & <0.1 & <0.1 & <0.1 & <0.1 \\ \text { Cobalt-60 } & <0.1 & <0.1 & <0.1 & <0.1 & <0.1 & <0.1 \\ \text { Strontium-90 } & <0.1 & <0.1 & <0.1 & <0.1 & <0.1 & <0.1 \\ \text { Ruthenium-106 } & 0.3 & 0.3 & 0.3 & 0.2 & 0.2 & 0.2 \\ \text { Iodine-131 } & 0.2 & 0.2 & 0.2 & 0.2 & 0.2 & 0.2 \\ \text { Cesium-137 } & <0.1 & <0.1 & <0.1 & <0.1 & <0.1 & <0.1 \\ \text { Plutonium } & 7 & 6 & 5 & 4 & 3 & 2\end{array}$

${ }^{a}$ The detectable dose shown in the table represents the accumulated 50-year whole body effective dose equivalent (ICRP 1979) expressed in multiples of the dose from naturally occurring radioactivity normally expected to be received by a person during a 50 -year period (i.e., 5 rem). Thus, a detectable dose of $<0.1$ means that the capability of the bioassay measurements is better than that needed to detect an accumulated effective dose equivalent of $0.5 \mathrm{rem}$.

-- Bioassay measurement not applicable for this situation. 
The table shows that, in general, the bioassay measurements that were performed are good for detecting the presence of radioactivity in the body resulting from chronic exposure to radioactive materials in the environment. Except for plutonium, the bioassay measurements could have detected the presence of radioactivity producing radiation doses equivalent to or less than the doses received from naturally occurring environmental radioactivity (i.e., cosmic rays, uranium in rocks, etc.). Exposures of similar magnitudes to plutonium in the environment are more difficult to detect right away because the quantity involved is so small. However, after about 10 years of chronic exposure, the measurements could detect a plutonfum level in the body that would result in the accumulation of a dose of about four times the amount that is nomally received from natural environmental radiation sources.

The table also shows that the bioassay measurements could detect radioactivity in the body from acute intakes that might occur following an accident. The ability of the measurement to detect an acute intake is dependent on the length of time the material remains in the body and the elapsed time from the intake to the bioassay measurement. For example, an acute intake of plutonium occurring 40 years ago and resulting in a dose equivalent of four times that received from naturally occurring environmental radioactivity could be detectable. As another example, acute intakes of cobalt-60 or ruthenium-106 could also be detectable, but only for about 5 years from the time of intake. The removal rate of the radioactive material from the body by both physical and biological process determines the length of time that a material can be detected after an exposure occurs.

\section{CONCLUSIONS}

Bioassay measurements of participating individuals gave no evidence of the presence of radioactivity other than naturally occurring potassium- 40 in any specific individual.

Where possible, statistical techniques were used to evaluate the results of the individual measurements grouped together. This was done to determine if the individuals, as a group, contained low levels of radioactivity that would 
not be detectable by a single measurement on any one individual. The statistical analyses indicated that the individuals, as a group, contain normal levels of tritium. The statistical tests did not provide evidence of any other types of radioactivity that might be associated with Hanford. Tritium is expected to be present in all individuals because of the worldwide presence of tritium in the environment.

Although the current measurements do not provide any evidence of unusual or unexpected levels of radioactivity in the tested individuals, the significance of the results in terms of evidence of past exposures must be inferred. The inference is made through the use of mathematical models that predict bioassay measurement results at various times following an intake.

Analysis of bioassay measurement capabilities showed that, within certain time constraints, the bioassay measurements would be capable of detecting an internal radiation exposure of about the same magnitude as that normally received from naturally occurring environmental radiation. For example, ruthenium-106 could be detected by a bfoassay measurement up to 5 years after intake: and acute intakes of plutonium could be detected for up to 40 years. Tritium and iodine-131, however, could not be reliably detected at one year following an acute intake resulting from an accidental release, but could easily be detected if intakes are continuous such as from routine effluents. 


\section{REFERENCES}

Brownlee, K.A. 1965. Statistical Theory and Methodology in Science and Engineering. Wiley, New York.

Price, K.R., J.M.V. Carlile, R.L. Dirkes, R.E. Jaquish, M.S. Trevathan, and R.K. Woodruff. 1985. Environmental Monitoring at Hanford. PNL-5407, Pacific Northwest Laboratory, Richland, Washington.

International Commission on Radiological Protection (ICRP). 1979. Limits for Intakes of Radionuclides by Workers. ICRP Publication 30, Pergamon Press, New York.

Environmental Protection Agency (EPA). 1985. Environmental Radiation Data Report 42. EPA 520/5-85-031, Eastern Envi ronmental Radiation FaciTity, Montgomery, Alabama.

UNSCEAR. 1972. Ionizing Radiation: Levels and Effects - Volume I: Levels. A report of the United Nations Scientific Committee on the Effects of Atomic Radiation (UNSCEAR) to the General Assembly, with annexes. New York. 
APPENDIX A

CHARACTERISTICS OF STUDY PARTICIPANTS 
APPENDIX A

CHARACTERISTICS OF STUDY PARTICIPANTS

Summary of Questionnires Completed by Examinees

\begin{tabular}{cr} 
1. Age & No. \\
\hline$<10$ years & 10 \\
$11-20$ & 4 \\
$21-30$ & 7 \\
$31-40$ & 11 \\
$41-50$ & 7 \\
$51-60$ & 20 \\
$61-70$ & 19 \\
$>71$ & 5 \\
Not given & 6
\end{tabular}

\begin{tabular}{ll} 
2. Sex & No. \\
\hline Males & 47 \\
Females & 42
\end{tabular}

3. Weight

Male Female

4. Occupation No. No.

$\begin{array}{lrr}<100 \text { Ibs } & 4 & 4 \\ 101-120 & 2 & 5 \\ 121-140 & 2 & 11 \\ 141-160 & 7 & 5 \\ 161-180 & 6 & 5 \\ 181-200 & 13 & 5 \\ 201-220 & 5 & 2 \\ 221-240 & 0 & 0 \\ 241-260 & 2 & 0 \\ \text { Not given } & 6 & 5\end{array}$

Farmer 38

Farm Laborer 3

Farm Wife 18

Child 12

Professional 7

Clerk 2

Retired

Not given

5. Time In Area No. No.

6. Consumed Wild Game No.

$\begin{array}{lr}<10 \text { years } & 14 \\ 11-20 & 16 \\ 21-30 & 30 \\ 31-40 & 15 \\ 41-50 & 5 \\ 51-60 & 1 \\ 61-70 & 2 \\ \text { Not given } & 6\end{array}$

Several meals/week 1

Several meals/month 3

Several meals/year 7

None

Not given

7. Previous employment at Hanford or other nuclear facility:

$\begin{array}{lr}\text { Yes } & 2 \\ \text { No } & 76 \\ \text { Not given } & 11\end{array}$

A. 1 


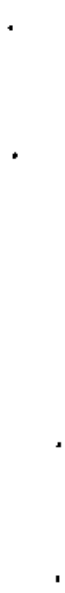


APPENDIX B

WHOLE BODY COUNT METHODS 


\section{APPENDIX B}

\section{WHOLE BODY COUNT METHODS}

The whole body counting facilities for the Hanford Site are among the most sophisticated in the world. The Hanford Mobile Whole Body Counter is a semiportable sodium-iodide detector based unit comparable in radioactivity detection capability to that of the main whole body counting facility in Richland. Because of the diagnostic capabilities available at the main facility, it was planned to use the main facility to perform quantitative assessment of radioactivity levels if radioactivity of potential Hanford origin was detected in the examinations at the Chiawana Grange Hall.

The data analysis procedure for each examination involved the comparison of the net integral of observed radiations in energy regions of the spectrum, corresponding to radionuclides of interest, to a predetermined threshold level. Such "observed radiations" are counted by the whole body detector and thus are generally referred to as "counts". The threshold level was calculated by determining the expected variability of the net counts in the varjous energy regions based on measurements of a group of subjects assumed to have no internal radioactivity other than natural background. The net counts for a particular energy region is the total number of counts in the region minus the number estimated to be due to scattered radiations based on counts observed in energy regions bordering the region of interest.

The threshold level for each region of interest was established at three standard deviations above the expected net counts. Thus, the threshold value represents an a priori decision to accept, with a probability of occurrence of $1 \%$, that the measurement could falsely detect radioactivity in a subject who actually had no internal radioactivity. Conversely, the procedure has a $99 \%$ probability of detecting radioactivity in excess of the stated detection 1 imit.

For each examination, the net counts in the energy regions of interest were compared to the predetermined threshold level. If the observed level exceeded the threshold level, the corresponding radionuclide was concluded to be present. The quantity of the radionuclide in the subject was then calculated by 
correcting the net counts for radioactivity assumed to be external to the subject (e.g., potassium-40 in the detector itself or radon and thoron radionuclides on the skin and hair) and applying the appropriate calibration factor from Table B.1.

The calibration factor for each radionuclide was determined by placing known amounts of the radionuclide of interest in an anthropomorphic phantom and then performing a standard whole body examination with the phantom as the subject. The phantom used for calibration was the BOMAB (bottle manikin absorption) phantom. The BOMAB phantom consists of 10 polyethylene bottles of sizes that, when appropriately arranged, approximate the size and shape of a standard adult. The ratio of the net number of counts in the energy region of interest to the known quantity of the radionuclide in the phantom is the calibration factor.

TABLE B.1 Calibration Factors for BOMAB Phantom

Radionuclide

potassium -40

manganese-54

cobalt -60

zinc -65

rutheni um-106

iodine-131

cesium-137
Calibration Factora

9.35

68.6

60.2

30.4

17.2

75.9

63.4

\footnotetext{
${ }^{a}$ Counts per minute in principal energy region per nanocurie.
} 
APPENDIX C

WHOLE BODY COUNT DATA 
APPENDIX C

WHOLE BODY COUNT DATA

As described in Appendix $B$, a radionuclide of interest was identified if the net integral observations in the corresponding energy region exceeded a threshold value that was calculated before the study began. Table C.1 shows the net integral observations in the energy regions of interest for seven radionuclides. The values of the corresponding thresholds are given in brackets at the top of each column of data.

As shown in the table, with the exception of potassium-40, none of the threshold values were exceeded. Potassium- 40 levels in the subjects ranged from 0.048 microcuries in a 4-year-old child to 0.16 microcuries in an adult male. These values are within the range that would normally be expected for such a group of people (UNSCEAR 1972).

Figure C.1 shows averages of the energy spectra obtained during the course of the examinations. The two curves show the average spectra obtained from the eight individuals that had interfering levels of naturally occurring radioactivity on their clothing during their initial examination and the average spectra from the 88 valid measurements. The bottom curve includes the followup examinations performed on the eight individuals after their clothing change. The principal energy regions for radionuclides of potential Hanford origin are shown below the curves, and the energy regions for radionuclides associated with naturally occurring radioactivity are shown above the curves. Averaging the data from the individual examinations reduces the variability inherent in individual measurements. The procedure thus produces a smoother spectrum and enables peaks within specified energy regions to be more noticeable.

Figure C.2 shows spectral data for the eight subjects who had interfering levels of naturally occurring radioactivity on their clothing. The curves compare the spectrums obtained from the individuals before and after clothing change. The presence of low levels of the naturally occurring radionuclides 
TABLE C.1. Summary of Whole Body Count Spectrum Analyses

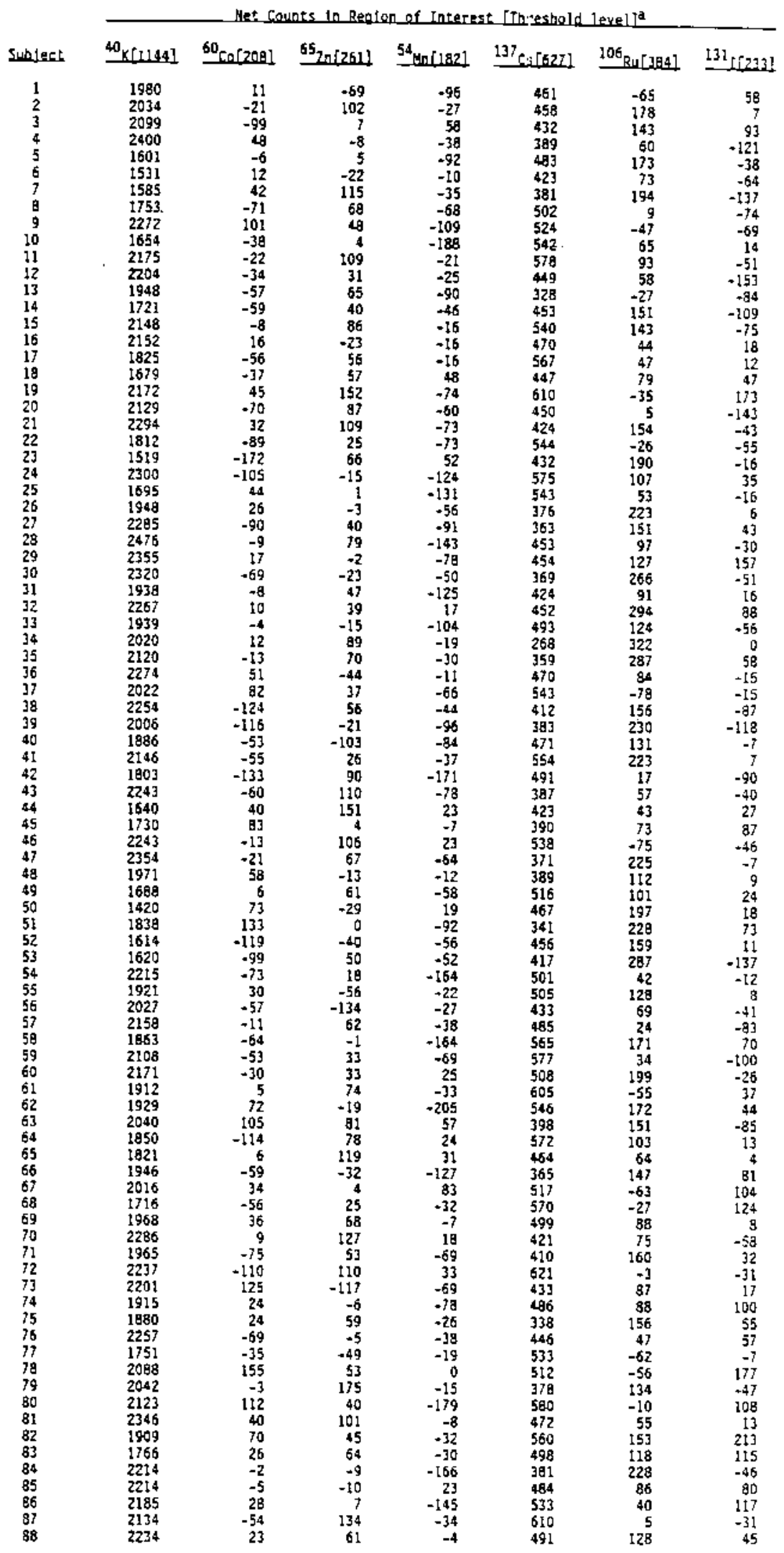

a Het counts in energy region * gross counts in region ninus est 1 mated backgraund count in region. The threshold $1 \mathrm{~s}$ the number of net counts in the energy region that wuld be required for posftive identification as described in Appendix 


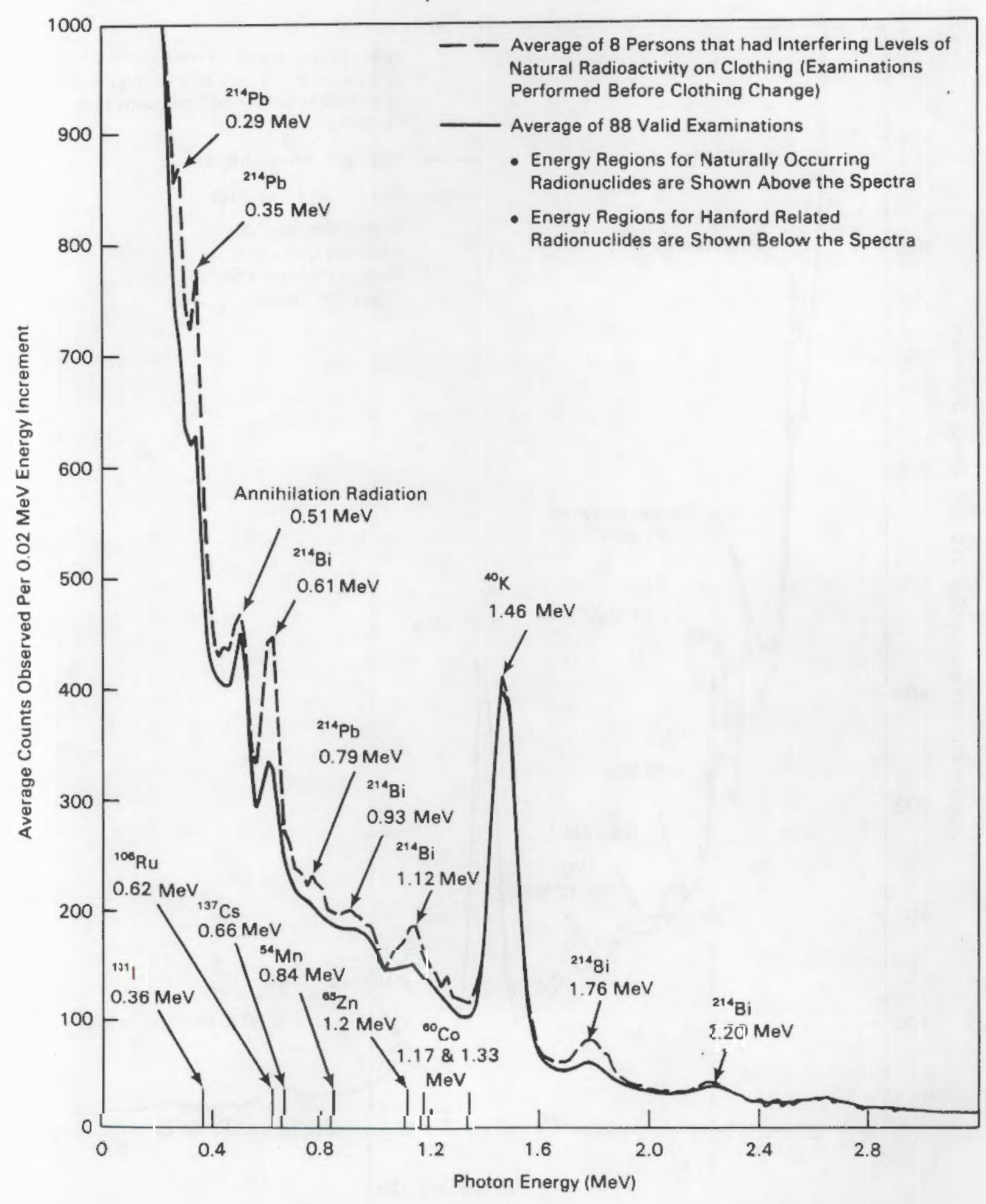

Figure C.1. Summary of Whole Body Count Spectra 


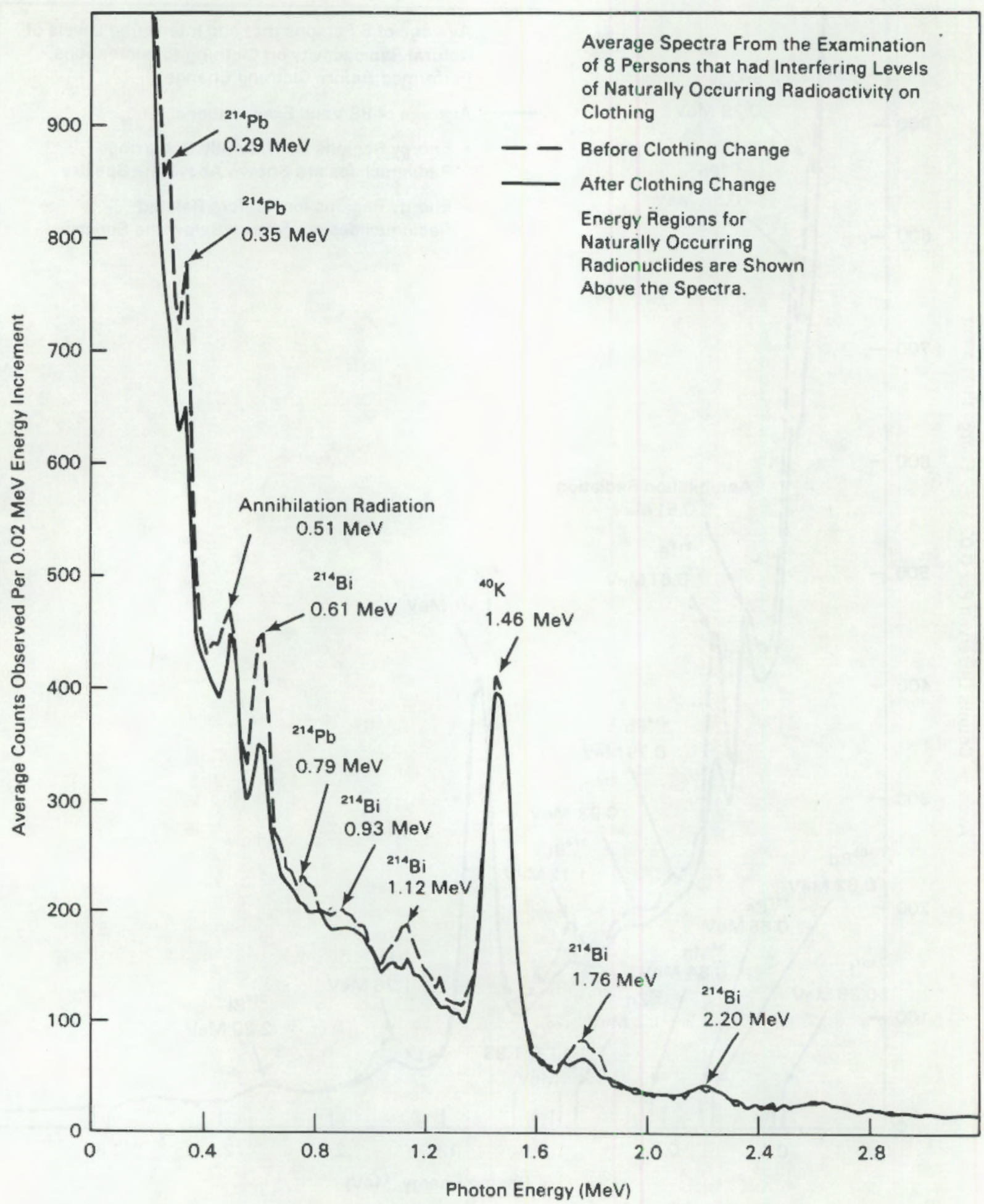

FIGURE C.2. Comparison of Spectra Obtained From Individuals With Interfering Levels of Natural Radioactivity on Clothing 
is reduced but is still apparent even after the clothing change. This is attributed to the presence of the radionuclides on underclothing and in the hair. Experience has shown that levels of such naturally occurring radionuclides that are external to the body can be essentially completely removed only by a shower and clothing change inmediately before the examination. 
. 
APPENDIX D

URINALYSIS METHODS 


\section{APPENDIX D}

\section{URINALYSIS METHODS}

Urine samples were processed by U.S. Testing Company, Inc., at their Richland, Washington, laboratory. Upon receipt, the samples were transferred to a large glass beaker and dilute acid was added to prevent plateout. With the exception of tritium, $500 \mathrm{~mL}$ alfquots were used for analyses. Tritium was measured by direct counting of the sample using a liquid scintillation spectrometer. One milliliter of sample was diluted by $15 \mathrm{~mL}$ of scintillation solution for the measurement.

Strontium- 90 was determined by chemical separation of the strontium from the sample through sequential precipitation as the nitrate and then as the carbonate. Iron and final traces of other elements were removed by a hydroxide scavenge. The yttrium-90 decay product was allowed to grow into equilibrium with the strontium-90, then separated and counted using a low-background beta proportional counter. Strontium-85 was used as a yield monitor.

Plutonium was determined by chemical separation of the plutonium from other elements by dissolution in nitric acid, absorption on anion exchange resin, and washing of the resin by nitric acid and hydrochloric acid. The plutonium was then desorbed from the resin, electroplated on a counting disk, and counted using an alpha spectrometer. Analysis of the alpha spectrum enabled determination of plutonium-238 and plutonium-239/240 individually. Plutonium-242 was used as a yield monitor.

Along with the samples, blank and spiked quality control samples were processed to monitor the performance of the overall procedures. 


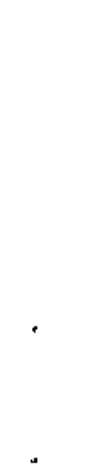


APPENDIX E

URINALYSIS DATA 
TABLE E.1. Urinalysis Data

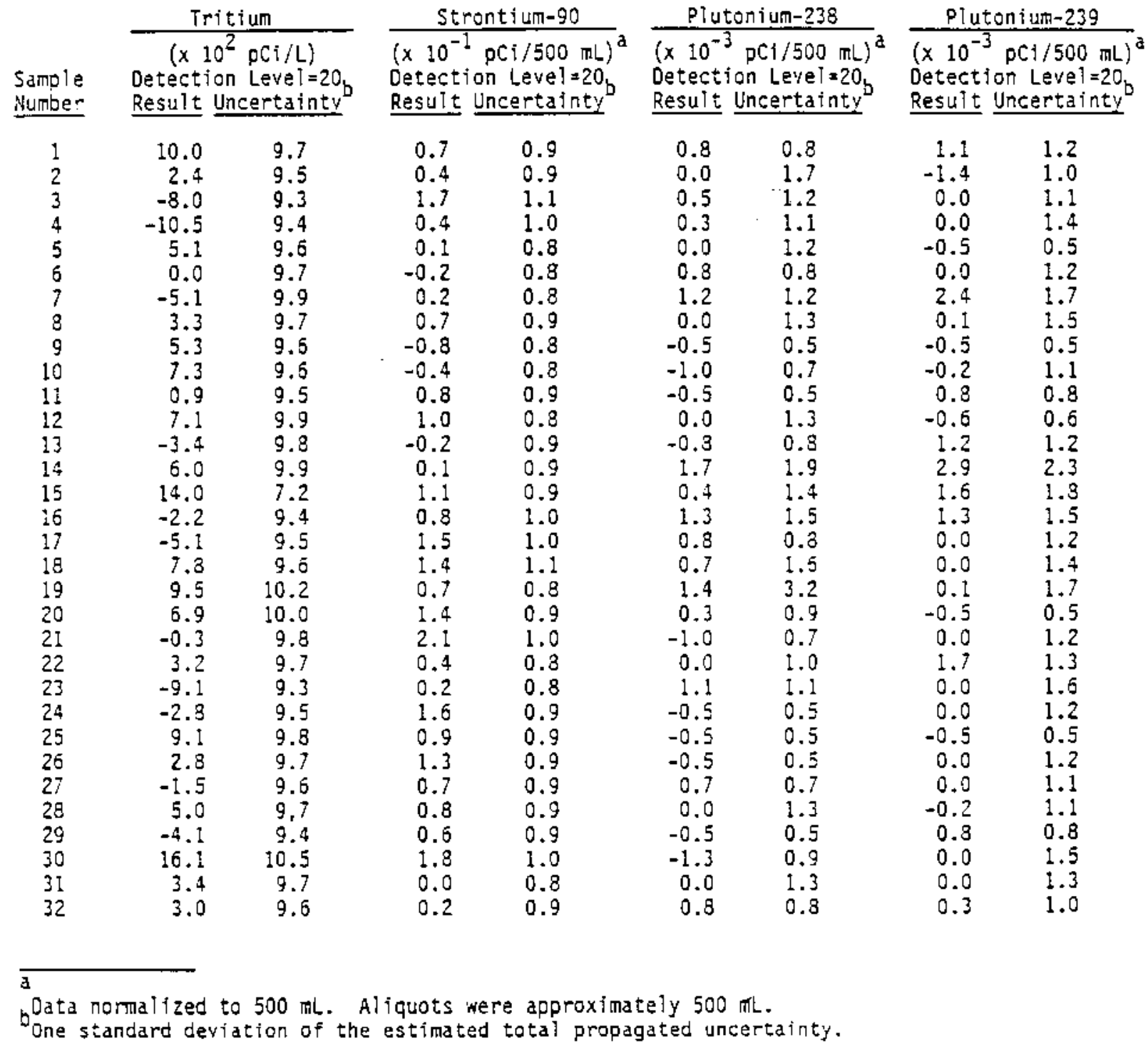


APPENDIX F

URINALYSIS STATISTICS 


\section{URINALYSIS STATISTICS}

The urinalyses results were grouped by radionuclide. Normally, for strontium-90, plutonium-238, and plutonfum-239, the data from the lab are reported uncorrected for biases that may be introduced by the presence of radioactivity introduced during the analytical process because the levels are below that of concern. Therefore, the grouped data were compared to results obtained from analysis of reagent blanks to check for any statistical difference. That is, the reagent blanks served as a control group. The uncorrected urine data for strontium-90 are given in Table F.1 and the data for plutonium are given in Appendix E. The urine data were not statistically different from the reagent blanks using the two-sample t-test for unequal variances at the $95 \%$ significance level (Table F.3). Thus the urine contained no detectable quantities of strontium-90, plutonium-238, or plutonium-239.

As shown in Table F.2, the strontium-90 analytical procedure apparently causes a statistically significant bias in the reported results if no correction is applied. This makes the uncorrected strontium-90 data shown in Table F.I appear to have many positive values. Therefore, the strontium-90 results reported in Appendix $E$ were corrected for the reagent blank activity. The bias introduced during the plutonium analytical procedure were regarded as insignificant, and thus no corrections were applied to the plutonium data.

For the tritium analyses, the reagent background was subtracted along with the counter background as part of the analytical procedure. Thus, the comparison of the group data to reagent blanks could not be made. Instead, the mean of the tritium results was tested to determine if it was statistically different from zero. Using a one-tailed t-statistic at the $95 \%$ significance lever, it was determined that the mean of the reported tritium results was different from zero. This was interpreted to mean that as a group, the urine samples apparently contain low levels of tritium. The calculated mean and standard error of the mean for the tritium data were $240 \pm 110 \mathrm{pCi} / \mathrm{L}$. 
Two samples received replicate analyses. The tritium result for sample 15 is based on a total of five determinations, and the plutonium-238 result for sample 19 is based on three determinations. The multiple determinations were performed because of uncertainties regarding the validity of the initial determination. The reported results are the average of the determinations including the initial determination. All other results are based on a single analysis.

TABLE F.1. Stronium-90 Results Uncorrected For Reagent Bias

\begin{tabular}{|c|c|c|}
\hline \multirow[b]{2}{*}{$\begin{array}{l}\text { Sample } \\
\text { Number }\end{array}$} & \multicolumn{2}{|c|}{ Strontium- 90} \\
\hline & $\begin{array}{r}\left(x 10^{\circ}\right. \\
\text { Resuit } \\
\end{array}$ & $\begin{array}{l}1 \mathrm{pCi} / 500 \mathrm{~mL}) \\
\text { Uncertaintya }\end{array}$ \\
\hline 1 & 2.4 & 0.3 \\
\hline 2 & 2.2 & 0.3 \\
\hline 3 & 3.4 & 1.0. \\
\hline 4 & 2.1 & 0.3 \\
\hline 5 & 1.9 & 05 \\
\hline 6 & 1.5 & 0.13 \\
\hline 7 & 1.9 & 0.7 \\
\hline 8 & 2.4 & 0.13 \\
\hline 9 & 1.0 & 0.15 \\
\hline 10 & 1.3 & 0.7 \\
\hline 11 & 2.5 & 0.3 \\
\hline 12 & 2.8 & 0.7 \\
\hline 13 & 1.6 & 0.13 \\
\hline 14 & 1.8 & 0.3 \\
\hline 15 & 2.8 & 0.3 \\
\hline 16 & 2.5 & 0.9 \\
\hline 17 & 3.2 & 0.9 \\
\hline 18 & 3.1 & $1.1)$ \\
\hline 19 & 2.4 & 0.7 \\
\hline 20 & 3.1 & 0.3 \\
\hline 21 & 3.8 & 0.3 \\
\hline 22 & 2.1 & 0.7 \\
\hline 23 & 1.9 & 0.7 \\
\hline 24 & 3.4 & 0.13 \\
\hline 25 & 2.6 & 0.7 \\
\hline 26 & 3.0 & 0.3 \\
\hline 27 & 2.4 & 0.7 \\
\hline 28 & 2.5 & 0.7 \\
\hline 29 & 2.3 & 0.7 \\
\hline 30 & 3.5 & 0.13 \\
\hline 31 & 1.7 & 0.7 \\
\hline 32 & 1.9 & 0.7 \\
\hline
\end{tabular}

\footnotetext{
$\mathrm{a}_{\text {One standard deviation of the estimated total }}$ propagated uncertainty
} 
TABLE F.2. Reagent Blanks

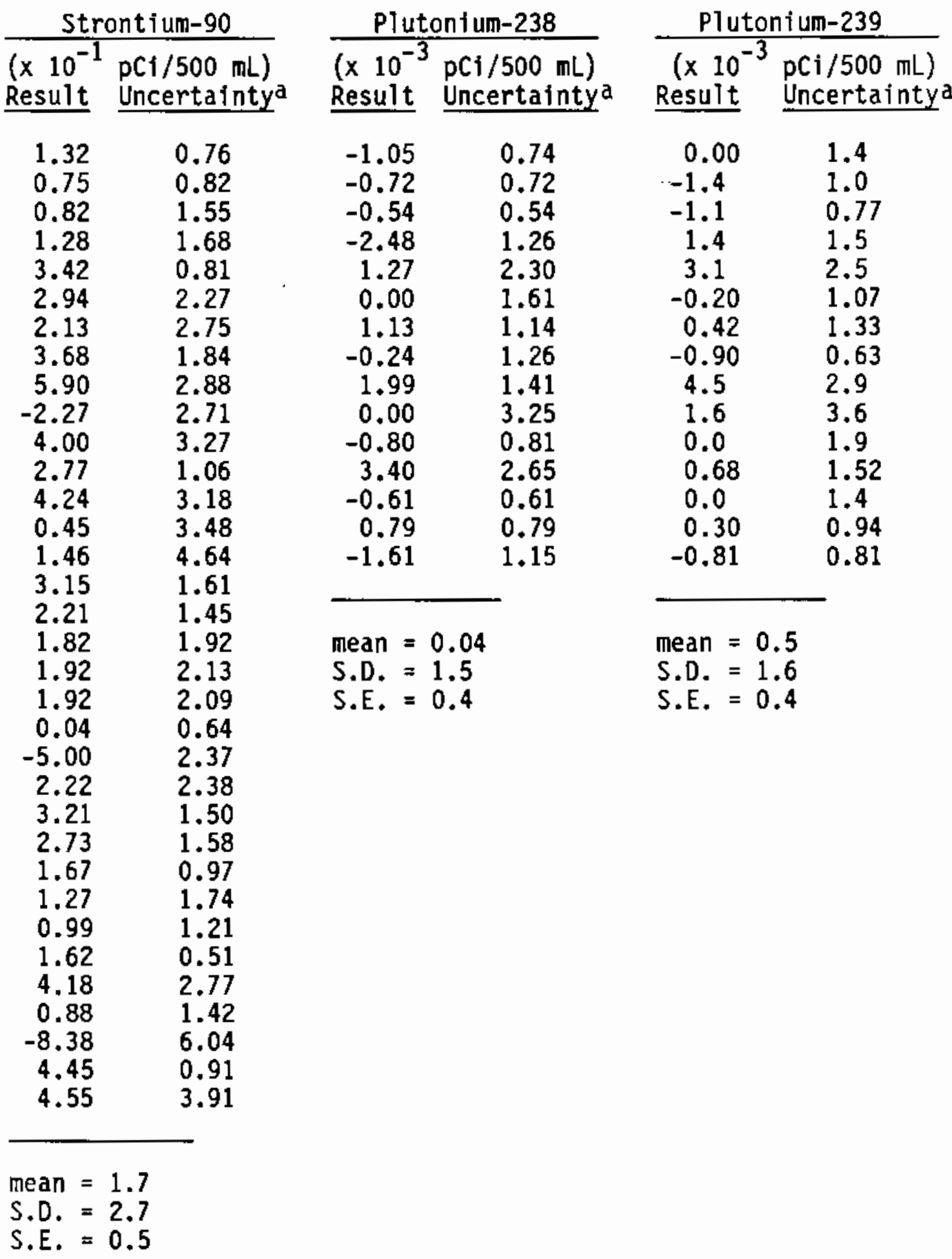

\footnotetext{
a One standard deviation of the estimated total propagated uncertainty. S.D. = standard deviation

S.E. = standard error of mean
} 


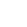




\section{DISTRIBUTION}

No. of

Copies

OFFSITE

30 Technical Information Center

OTHER

R. R. Mooney

Washington State Department of Social and Health Services 1409 Smith Tower

Seattle, WA 98104

R. D. Paris

Radiation Controls Section Oregon State Health Division P.0. Box 231

Portland, OR 97207

\section{ONSITE}

\section{DOE Richland Operations Office}

D. R. Elle

T. R. Fitziminons

R. E. Gerton

S. H. Leroy (5)

M. J. Plahuta

K. J. Wheeless

G. R. Yesberger (5)

DOE Public Document

Reading Room

Hanford Environmenta I Hea 1 th Foundation

B. D. Breitenstein

J. A. Jones Construction Company

D. J. Foust

Rockwe [1 Hanford Operations

J. F. Albaugh
No. of

Copies

2 U. S. Testing Company, Inc.

M. M. Lardy

A. V. Robinson

UNC Nuclear Industries, Inc.

D. F. Brende?

Westinghouse Hanford Company

R. 0. Budd

51 Pacific Northwest Laboratory

T. L. Aldridge

W. J. Bair

D. E. Bihl

P. E. Bramson

R. L. Buschbom

E. G. Carbaugh

L. G. Faust

G. R. Hoenes

J. R. Houston

R. E. Jaquish

J. J. Jech

H. V. Larson

W. D. McCormack

B. A. Napier

H. E. Palmer

K. R. Price

L. L. Rader

M. C. Rhoads

G. A. Riekst.s

J. K. Soldat

J. V. Stangeland

M. J. Sula (20)

C. M. Unruh

W. R. Wiley

Publishing Coordination (2)

Technical Information (5)

Health Physics Department Library 
